Work, employment and society

\title{
Macho, mobile and resilient? How workers with impairments are doubly disabled in project-based film and television work
}

\section{Keith Randle}

University of Hertfordshire, UK

\section{Kate Hardy}

Leeds University, UK

\begin{abstract}
Inequalities in the creative industries are known to be persistent and systemic. The model of production in UK film and television (UKF\&TV) is argued to exclude on the basis of gender, race and class. This article considers a social category that has been overlooked in these debates: disability. It argues that workers with impairments are 'doubly disabled' - in both the labour markets and labour processes of UKF\&TV. It concludes that disability cannot simply be incorporated in an additive way in order to understand the exclusion of these workers, but that they face qualitatively different sources of disadvantage compared with other minorities in UKF\&TV workplaces. This has negative implications for workers with impairments in other labour markets, as project and network-based freelance work, a contributor to disadvantage, is seen as both increasingly normative and paradigmatic.
\end{abstract}

\section{Keywords}

disability, double disablement, exclusion, film, impairment, project-working, television

\section{Introduction}

Research on the 'creative economy' has demonstrated that far from embodying 'unfettered social mobility for all' (Florida, 2005: 79), there is overwhelming

\section{Corresponding author:}

Keith Randle, Hertfordshire Business School, University of Hertfordshire, De Havilland Campus, College Lane, Hatfield ALIO 9AB, UK.

Email: K.R.Randle@herts.ac.uk 
evidence of persistent social inequalities. These have been argued to be inherent in the industry due to its dominant model of production: project-based work (Eikhof and Warhurst, 2013). Research specifically on inequalities in the UK film and television industries (UKF\&TV), a part of the creative economy, has focused largely on gender, race and, to some extent, class, while little attention has been paid to impairment. People with impairments are arguably the most excluded demographic in UKF\&TV, accounting for 11.6 million people in 2014, around 18 per cent of the UK population as a whole (UK Government, no date) but only 0.8 per cent of the audiovisual media industries (UK Film Council (UKFC), 2003). Yet little is known about the specific ways in which project-based work impacts on this group. This article addresses this by examining the particularities of the relationship between the working practices which emanate from project-working and a group of workers who, it is argued, are doubly disabled by them. It explores the experiences of workers in UKF\&TV who have what can be described as severe forms of physical and sensory impairment (see Appendix 1).

'Double disability' occurs as a function of two sites of disablement. The first is the labour market for project work, where entry and exit is frequent and where, it is maintained, a 'dark side' of social capital (Antcliff et al., 2007) or 'catnets' (Rydgren, 2004) may operate to disable workers with impairments. These features of UKF\&TV are widely accepted to also exclude on the basis of gender, race and class. The second site is the labour process itself which, in contrast to the labour market, has been more marginal in understandings of the persistence of inequalities in UKF\&TV. A focus on this is important as it affects impaired workers in specific ways. It should be noted, however, that these inequalities are not experienced uniformly and are mediated by different production processes and organizational settings (e.g. commercial or public service television), different types of impairment and by other intersecting social relations including gender, race and class.

In the following section, the framework through which disability is understood in this article is outlined. Subsequent sections describe the workplace context within which interviewees are located (UKF\&TV) and the methodology of the study. Empirical data are then presented. A conclusion demonstrates how the theoretical perspective developed contributes to our knowledge of inequalities in UKF\&TV specifically and in projectbased work more generally.

\section{Theorizing disability: the social model and the 'ideal worker'}

Attitudes towards disability are shaped by their historical contexts. In pre-industrial societies, impairment did not represent an affront to the norm, but during the enlightenment and under industrial capitalism, work became rationalized and designed with less place for 'disorder' (Hughes, 2002). Disabled people were taken out of the home, previously the site of much work, and deposited into institutions. Other accounts, however, have questioned any simplistic 'stage theory of history' (Roulstone, 2002: 631), pointing, for example, to 'the parallel co-existence of large-scale exclusionary factories and small-scale shop, workshop and family-run businesses' during the 19th century, with the latter being more inclusive (2002: 632). Thus, it is necessary to consider how the 
very specific and particular relations of work and employment impact on the experience of disability within any historical conjuncture or mode of production.

One basis for exclusion from the contemporary workplace is the perception that disabled people are not able to conform to modern, capitalist forms of work discipline, characterized by strict temporalities, abstract and disembodied job design and inflexible job descriptions (Barnes and Mercer, 2003). Ableist values are not only written into the core of job design, but into the fabric of modern capitalist production itself (Foster and Wass, 2012). Unlike the standardization of Fordist production principles, which Foster and Wass (2012: 708) argue were better suited to people with impairments, 'post-Fordist principles ... emphasise jobs designed around multiple-tasking, interchangeability and team working', where such jobs are 'likely to disable an impaired employee'. Without wishing to subscribe to epochal characterizations of the organization of work, it is the particular form 'post-Fordist' work in the UKF\&TV sector takes and the ways in which people with impairments are unable to conform, which underpins this article. The terms 'non-standard', 'project' and 'contract-based' work are used to describe these types of employment relations.

The dominant explanatory framework in disability studies is the social model of disability (Oliver, 1983), which focuses on barriers - the social structures and processes that disadvantage and exclude - rather than individuals and/or their impairments. From this perspective, disability is produced by economic, political, cultural and attitudinal patterns and structures rather than specific impairments (Oliver, 1996; Shakespeare, 2014; Thomas, 2007). Applied to work and employment this perspective might be summarized as follows: if nature or the physical world is the source of impairment of the worker, the capitalist labour market and work organization is the dominant source of his/her disability. Acknowledging that the social model remains 'hotly debated and contested' (Thomas, 2007: 6) and subject to theoretical critiques (Shakespeare and Watson, 2002; Terzi, 2004), this article draws on the framework in order to highlight the disabling processes experienced by workers with impairments in UKF\&TV and the ways in which these impact on their work opportunities.

The concept of the 'ideal worker' describes a human component of the labour process who is 'always ready, willing and able to work' (Cooper, 2000: 395) and presupposes a gendered (masculine) subject without caring responsibilities, whose primary responsibility is to perform paid work. This requirement is exemplified in UKF\&TV, which is characterized by short-term contracts, long, intensive working days and a high-speed labour process. While the construct of the ideal worker has been shown to be gendered by many authors (Acker, 1990; Kelly et al., 2010; Rees-Davies and Frink, 2014), it is argued here that it is also contingent on the assumption of an able and resilient body, which can conform to the fluctuating demands of the employer (Foster and Wass, 2012). Disability intersects with all aspects of identity since it 'affects people of all classes, races, ethnicities, and religions, male and female, straight and gay' (Hirschman, 2012: 397). Yet it is only recently that disability has come to feature in discussions of intersectionality and is routinely absent from studies of work and employment. How the intersectional nature of social vectors can be understood remains a vexed question (Carbado, 2013; Yuval-Davis, 2006), but is nevertheless useful as a concept to identify the different systems and structures of oppression and exploitation 
which operate simultaneously to shape individuals' experiences at work. As such, while the focus here is on impairment as a source of disadvantage, it is important to hold in tension these various structures which differentially shape workers' experiences and opportunities.

\section{Systemic disadvantage in the creative industries}

The question of why minorities are under-represented in any given work context is complex and a comprehensive discussion is beyond the scope of this article. To fully understand the absence of individuals with particular characteristics would certainly involve taking account of the mechanisms by which those aspiring to join the workforce are selected and the workplace dynamics which influence retention and promotion. However, it would also require an exploration of the wider forces which shape aspiration. These might include: family, educational, peer and media influences; the existence, or otherwise, of role models; and the overarching culture which shapes understandings of who might be the appropriate occupants of specific job roles.

This latter point is addressed by Scharff (2015) who, in examining equality and diversity in classical music, refers to the understanding in contemporary Western mythology that the artist is male. Equally, a report on admission into art and design courses (Burke and McManus, 2015: 7), a key route into art and design jobs, concludes that the academy has 'a deeply embedded, institutionalised class and ethnically biased notion of a highly idealised student against whom they measure applicants'. This bias is not necessarily acknowledged by those responsible for admissions, neither is it based, for example, on a preference for white middle-class applicants per se or prejudice against ethnic minority or working class applicants. Rather, it is premised upon a belief that attributes more likely be associated with whiteness and a middle-class upbringing are necessary to meet the requirements for success on these programmes of study.

Eikhof and Warhurst (2013) argue that the creative industries production model encompasses systemic social inequalities, generating employment practices which discriminate on the basis of sex, race and class. Drawing on a substantial body of research on inequalities in the creative industries, they point to three features of employment practices emerging from this model which disadvantage minorities: employment instability and low wage entry jobs; recruitment practices; and working patterns which include long and unsociable hours, and substantial travel.

Taking the first of these, employment instability and low wage entry jobs, 'non-standard' employment contracts (Cranford et al., 2003) are extremely widespread in UKF\&TV. The project-based nature of production in these industries obliges many of those working in it to re-enter the labour market on a regular basis and search for new employment, with one study indicating an average work project of 7.4 weeks in film production (Blair, 2001). In 2012, self-employment was most apparent in this sub-sector (46\% against a UK average for all industries for self-employment of 15\%), while in distribution and exhibition most were permanently employed (British Film Institute (BFI), 2013). In television the movement towards flexibility of employment and industry fragmentation has gathered pace since the Broadcasting Act of 1990 (Dex et al., 2000; Saundry, 2001). Prior to 1979 , nearly all jobs in the BBC and ITV were 'staff', but more recent estimates 
put this at 45 per cent (Born, 2004). Consequently, UKF\&TV is characterized by a workforce with a high proportion of freelancers working on short-term contracts (Bhavnani, 2007; Grugulis and Stoyanova, 2012; Holgate and Mckay, 2007). Shuey and Jovic (2013: 190) have found that "disabled workers who make multiple labor force exits and reentries across their work lives [have] higher odds of unmet needs [in relation to adjustments]'. They suggest that, as a result, these workers are vulnerable to future permanent exclusion from these labour markets.

For many prospective workers the only route into UKF\&TV is through internships, which often oblige them to work for free or for very little (National Union of Journalists (NUJ), 2007; PACT, 2007). The standard entry level job is the generalist role of 'runner' or production assistant (Ashton, 2014). Working for free is becoming increasingly common across cultural and media work (Holgate and Mckay, 2007; Low Pay Commission, 2011; Percival and Hesmondhalgh, 2014) with between 40 and 50 per cent of entrants spending some time in unpaid internships (Siebert and Wilson, 2013). This discriminates against many based on class, or membership of lower socioeconomic groups (Eikhof and Warhurst, 2013).

Second, recruitment practices also exclude workers on the basis of gender, race and class (Gill, 2002; Randle et al, 2007; Thanki and Jefferys, 2007). In this project-based environment, word of mouth recruitment predominates (Holgate and Mckay, 2007; Lee, 2011; Skillset/UKFC, 2008), leading workers to rely on both formal and informal networks as a means of finding work (Lee, 2011). The notion of the 'ideal worker' outlined earlier provides a template against which applicants for recruitment into film and television positions can be measured. Where return to the labour market is frequent, as in project-based work, and recruitment is informal - eschewing any checks and balances that formal procedures might at least aspire to impose - the opportunities for screening out those who do not fit this model, described here as incorporating notions of resilience, mobility and machismo, are regular and numerous.

A series of articles (Antcliff et al., 2007; Saundry, 2001; Saundry et al., 2006) explores employee relations in a de-regulated and consequently casualized and fragmented UK television industry, emphasizing the growth of freelancing and the related importance of networks and social capital. Antcliff et al. (2007) refer to 'open' and 'closed' networks where open networks allow those individuals who have powerful contacts to improve employment opportunities. However, they suggest that rather than being 'open and inclusive', these networks obscure the role of power relations and connections, since access to powerful contacts depends on factors such as 'status, reputation, ability, social and familial connections' (Antcliff et al., 2007: 388) where the latter connectivities are less available to minority groups.

Blair (2001) demonstrates how workers in the UK film industry have accommodated a similarly casualized labour market by forming 'semi-permanent work groups', often under the hierarchical control of a head of department. These groups have the function of reducing employment uncertainty. The director of photography, for example, would choose camera crew. Consequently, reputation and trust form vital elements in the selection process, emphasizing the importance of maintaining good relations with colleagues and continually demonstrating a required level of skill, competence and effort. As Antcliff et al. (2007) point out, individuals are obliged to abide by the norms imposed by 
those who control access to employment opportunities and broker information and who are therefore in positions of power.

In examining how exclusionary mechanisms operate, Rydgren (2004: 707) describes how 'statistical discrimination' occurs when an employer makes a decision based on beliefs about the typical characteristics of the group an individual is thought to belong to. Such beliefs are stereotypical in that they are oversimplified and based on group membership, rather than a specific understanding of an individual's skills. As well as possibly erroneous, these beliefs are often prejudiced, meaning that negative evaluations or feelings are applied to the group. In the case of disability, for example, this might mean that a decision is taken, firstly, on a belief that, overall, people with impairments perform less well as a group than those without impairments and secondly, that this applies equally to all members of the group. Rydgren (2004) argues that people use stereotypes as part of their thinking, often without reflection, to simplify everyday life. Networks can also exclude people by category as they 'tend to be biased towards homophily' (Rydgren, 2004: 711). This means that networks, through which labour market information spreads and membership of which can form the basis for appointment in some situations, are often composed of like individuals forming distinct categories. Rydgren (2004: 711) refers to these as 'catnets'.

In both film and television, therefore, it can be argued that informal mechanisms constructed to reduce uncertainty and increase security for individuals in casualized labour markets can have the reverse effect for some workers. This reflects the 'dark side' of social capital where 'networks that can enhance employment prospects also have the potential to destroy them' (Antcliff et al., 2007: 388).

The third element that Eikhof and Warhurst (2013) highlight - working patterns - is demonstrated to exclude, for example, women who found it hard to balance childcare with long, unsociable hours and substantial travel. However, working patterns, or the labour process, receive scant attention in comparison to the labour market and/or recruitment, even though the former constitutes a major part of the model of production.

Eikhof and Warhurst (2013), and the wider literature on which their article is based, demonstrate how workers are excluded in terms of gender, race and class. Less attention has been paid to workers with impairments, and disability remains an under-researched area in the creative industries. Estimates of the number of disabled workers reported as being employed in the film industry is very low, standing at somewhere between 2 per cent (Skillset, 2005: 28) and 0.8 per cent (UKFC, 2003: 8), though it is possible that practitioners fail to declare their disabilities unless they are visible, possibly due to fear of discrimination (Randle et al., 2007). There are no statistics on where disabled people who work in TV are employed, although Vasey (1997: 138) comments, 'my suspicion is that the majority of those who do creative work ... are working within disability-specific programming or at least got started there'. Many of the respondents reported in the present article had experience of working within such programming and it is argued that this separate sector was important in enabling people with disabilities to enter the industry, although it can ghettoize workers, forming a glass ceiling and a 'glass partition' (Roulstone and Williams, 2014) - a barrier to both vertical and horizontal career mobility.

Much existing research on disability, work and employment focuses on labour market or policy issues (see Berthoud, 2008; Jones and Wass, 2013) with a few notable 
exceptions focusing on the workplace (Fevre et al., 2013; Foster and Wass, 2012). There appear to be no published studies that examine the workplace experience of disabled workers in contexts where non-standard contracts (such as freelancing) are common, in the creative industries, or in highly qualified or professional work. No major academic research project in the UK has focused exclusively on disabled workers in UKF\&TV, although the study from which these data were derived included disability as a core element. This article asks two questions. First, what insights can be gained from the data reported here into the ways in which people with impairments experience discrimination and exclusion from film and television work? Second, are disabled people disadvantaged in the same ways as other under-represented minorities in getting in, engaging in the labour process and making careers within these sectors?

\section{Methodology}

The data that inform this article are taken from a research project which set out to explore the barriers to diversity in UKF\&TV employment and to review policies and interventions adopted to promote diversity and employment in the sector. The project took a qualitative, inductive approach and was undertaken in two phases. In the first phase, 28 in-depth, semi-structured, face-to-face, scoping interviews, averaging over an hour in length, were carried out with industry experts and those in support or broadcasting organizations with a responsibility for promoting diversity. The second phase involved 71 interviews with practitioners from under-represented groups. A mini life history approach (Robson, 1993) allowed participants to describe their work experiences over time and explored: job roles, entry, education and social background, employment status, work history, sources of labour market information, barriers to progress, training and feelings about their future in the sector. These interviews also averaged one hour and all but two of the interviews were recorded and transcribed. Content analysis was undertaken using NVivo software. At the research design stage a sampling grid was created identifying work roles from pre-production through to post-production. This formed the basis for contacting potential interviewees alongside possession of the demographic characteristics the research aimed to investigate. Purposive snowballing techniques were employed to ensure that the interviews would yield data that covered the research questions. The data, collected between 2006 and 2007, focus on the experience of disability in a labour market/employment context.

This article draws on 21 recorded and transcribed interviews with participants who declared a range of 'severe', generally visible, physical or sensory impairments (phocomelia - as a result of the use of thalidomide, dwarfism, deafness, blindness or were wheelchair users), but who all nevertheless achieved some measure of success in securing periodic work in the industry. Appendix 1 lists respondents, by job roles and impairments. None of the 21 interviewees explicitly declared any mental health impairment and this remains an important gap in the research.

Seventy-six per cent of those who completed monitoring forms were educated to degree level or above and less than 4 per cent reported having no qualifications. The largest age group was 30-39 (42.5\%), while the 18-29 and 40-49 age groups each made up 26 per cent and only 5.5 per cent fell into the 50-59 category. The male/female ratio was 
54/46 per cent, and 44 per cent were white British. The practitioners occupied job roles with different employment status including freelancers and industry professionals on both temporary and permanent contracts.

Of the 77 from the full sample of 99 who completed monitoring forms, 21 (27\%) reported a condition which would be recognized under the Disability Discrimination Act (2005). This constitutes a large proportion of the sample. The research team specifically focused on the experience of under-represented groups in the workforce. With very low levels of reported disability in the film and television industries, this can be viewed as a 'hard to reach' group and consequently the number of interviews carried out are regarded as providing significant qualitative data. A 'representative sample' of the UKF\&TV workforce involving 99 participants, as in this study, could have been expected to include either zero or one disabled interviewee with a declared disability.

\section{The experience of working with impairment in the UK film and TV sector}

Overall, workers with impairments reported forestalled careers and faced a range of limitations in working in UKF\&TV. Rowan stated: 'all the way through my career ... whatever I'm doing, it's always going to be my first film ... it's always going to be at an entry level ...'. Ben similarly reported that while other actors may establish 'sequential careers', there was a 'glass ceiling' for disabled actors:

There are no other ... able-bodied actors who have the lead in a romantic film for 90 minutes on BBC and then get offered nothing from the BBC for a whole year afterwards. That just doesn't happen to them ... if there's a sequential way a career goes, mine hasn't followed that ...

Ross (blind) said that despite year-on-year 'glowing' appraisals, he had been unable to progress in his career as a news reporter. He found it difficult to understand or articulate exactly which mechanisms were holding him back:

You don't know whether it's one individual blocking your path or whether there's a sort of general feel[ing], or that you're just being unlucky, you know, because it is a wildly competitive business and there are lots of people with very sharp elbows.

Glen (visual impairment), stated that he thought that a 'subliminal or subconscious attitude' meant that employers felt that people with disabilities should be satisfied with static jobs, rather than upwardly mobile careers:

They almost say, 'We'll give you a job, you should be happy with that'. You know? Never mind that you've been a researcher for the last 10 years while all your contemporaries have kind of moved up to assistant producer, producer and then executive producer.

Failure to move through the hierarchy meant there was a shortage of people with impairments in management positions who could act as role models or support other workers coming through. Morgan (wheelchair user) thought that managers with disabilities could play an important part both in controlling who was employed on a project, but 
also for making necessary adjustments in order to engender their inclusion. Paul similarly emphasized the importance of managers:

Unless the managers are equipped, confident, aware, it is ... it's a waste of time [having disabled workers in the system], so you've got to make sure, and often we do a lot of training with the managers.

There was, however, an unevenness in terms of the willingness of particular sectors of the industry to make adjustments or support the career progression of people with impairments. Judi said that some TV sectors were more supportive to adjustments, but in film the speed of production meant that they generally ignored or resisted making the accommodations she requested. Rowan described the attitude of one independent producer as thinking: 'Why should I even think about disability unless it's going to make me money? I'm in business, I'm not a charity'. The need for independent production companies to survive in a highly competitive environment meant that they were significantly less likely to accommodate disabilities. However, major broadcasters, including the BBC, have greater stability in their commissioning processes and, further, the publicly owned nature of the BBC means that - unlike the private sector - it is subject to the Equality Duty.

Workers who had been able to progress attributed this, to a significant extent, to the attitudes of co-workers and the implementation of adjustments and accommodations. However, most frequently they attributed success to the specific schemes and programmes available through major broadcasters, notably the BBC. Timothy identified the $\mathrm{BBC}$ as being very good at providing courses and training and Stephen stated that he had been able to use the Access to Work scheme at the BBC. Glen similarly said that 'the $\mathrm{BBC}$ as an employer does far more than any other employer I've ever come across to accommodate and encourage'. However, underlining the problems outlined above associated with mobility in the industry, he stated that they were 'good at getting people through the door; we're less good at either keeping them or promoting them'. The next section looks first at the labour market and then at the labour process to examine the reasons why people with impairments faced such high levels of disablement in their attempts to work and get on in UKF\&TV.

\section{The labour market: recruitment into UKF\&TV}

The standard route into UKF\&TV is as a 'runner', which normally involves very low (or no) pay. This entry point has been seen as limiting for those without the ability to work for below subsistence pay (Ashton, 2014). However, what has not been explored is the runner's labour process, which involves long hours and a requirement to respond quickly and be highly mobile. Nasir, a film-maker with cerebral palsy, worked with a helper, with whom he was interviewed. He indicated how his disability formed a barrier for him:

People start off as runners ... [and] I can't be a runner ... it's very hard for me ... you know, making cups of tea for people and it's long hours and stuff like that and I can't physically do that.

Morgan, a director and producer who used a wheelchair, concurred: 
What's the standard entry point into drama? Runner, you know? Which is crap ... . I'd be a terrible runner, as would, you know, [people with] lots of disabilities.

This role is particularly characteristic of 'post-Fordist' job design in that it is characterized by multiple and fast changing tasks which people with impairments can find particularly disabling, meaning that it presents them with specific complexities not faced by others. The standard entry route to the industry was therefore blocked to many people with impairments due to the intensity, variability of responsibilities and extremely long days, as well as the ability to survive a period on low income.

As an alternative, working in specialist programming catering to viewers with impairments was of central importance to the ability to enter the TV industry. Lori (phocomelia), began her career working as a researcher in this way, later moving into mainstream programming; Timothy (deaf) worked at the BBC on a programme for deaf viewers; and Stephen (wheelchair user) worked as a disability adviser for BBC Radio. Yet despite its role as an important mechanism for gaining a foothold in the industry, it was widely felt to be devalued within mainstream UK television, with specialist disability production seen as secondary:

People will perceive it to be poor quality before they've even seen it. ... You'll say, 'There's a play, and ...' 'Oh really?' And you say 'Yeah, and it's got disabled people in', and ... it just drops, it's a kind of ... 'Well ... it won't be as good'. (Paul)

Timothy (deaf) similarly emphasized that workers gained little recognition from work on specialist production: 'When you work on a programme like See Hear [a specialist programme for people with hearing impairment], nobody outside sees the value of what you do'. Schemes and specialist production were extremely important in enabling entry into the industry. However, their separation from the mainstream resulted in a lack of mobility or career path within the wider industry. Rowan described this as extremely frustrating, as, despite having evidenced all the necessary skills through her career to date, employers would respond that they did not have schemes for disabled people. She said:

It's like disabled people fit in schemes and a scheme's at entry level, so the perception of somebody developing a career or continuing in a career doesn't seem to be there.

This meant that although specialist production represented a crucial alternative entry route, it rarely presented an opportunity for horizontal career progression, but instead constructed a glass partition, often blocking movement into mainstream programming.

Despite the importance of specialist programming in at least providing a route into television work, broadcasting shifted towards integrationist approaches during the decade after 2000. In its 2002 'Statement of Promises', Channel 4 committed to 'build on the success of the 2001 Blinded season and keep disability firmly in peaktime' (Channel 4: http://www.channel4.com/about_c4/promises_2002/promises_voices.html). One of the ways it sought to do this was to commission a second series of $V e e ~ T V$, aimed at a deaf audience, though this was later cut. The result was that most of the people who had worked on the programme had to move outside of the media: 
One moved to social care, one's on work placement and the woman was telling me that she files envelopes ... and her skills are absolutely amazing. But she's been demoted to stuffing envelopes, which is a terrible shame ...' (John, deaf)

The integration or mainstreaming of disability programming in major broadcasting organizations does not appear to have benefitted disabled workers, as it has removed an important route of entry. At the same time, disability programmes appear to have been more easily dropped from mainstream broadcasting as a result of this policy.

For those who had been successful in accessing mainstream production, both Ross (blind) and Glen (visual impairment) argued that people with impairments were effectively excluded from some of the opportunities to network, which took place outside the workplace. They were:

not taking advantage of all the networking opportunities, ... you know, socializing and going to the pub or wine bar or theatre or whatever; the kind of thing that sort of makes you a fully paid up member of the club. (Glen)

These non-work time activities can exclude those with caring responsibilities, workers who do not drink alcohol or who have cultural reasons for not spending time in spaces where alcohol is consumed. In the case of people with impairments, the barrier to inclusion differed in that this was also due either to an inability to physically access those spaces, or to the fact that the physical environment complicated communication. For example, John's dependence on an interpreter hindered his participation. He suggested it was 'not natural' to have to rely on an interpreter in a social situation, which closed down the potential for generating the networks necessary for career progression or finding new work:

Unfortunately the media's more who you know and who you've worked with and I'm kind of cut off from that, because I can't go to the pub and sort of like talk to other producers and directors and network and really set up contacts, I have to bring an interpreter. (John)

Many respondents referred to the ways in which other social vectors intersected with disability to mean that individuals with impairments could not embody or enact the appropriate relations necessary for establishing networks. James (hearing impairment) argued that people with disabilities were generally less likely to have had exposure to the 'codes of behaviour' that were necessary 'to impress people and how to make them feel like you're someone to kind of recommend or look up to'. Rowan agreed that such class and whiteness-based cultural capital therefore intersected with impairments, creating diversity hierarchies:

The people who get through the door first are the white male disabled people, with maybe a foot missing or an arm missing, you know, something that actually doesn't significantly pose ... you know, operational problems ...

While disability is shaped and produced by its interaction with other structuring features, such as class, gender, race and age, respondents stated that diversity was often 
imagined one-dimensionally and that these intersections were not recognized. Ross (blind) argued, for example, that the current focus on race in the industry meant that 'gender and disability gets squeezed a lot, and I think the feeling certainly there was that [disability is] just not the same priority as race and gender'.

\section{The labour process}

In addition to barriers to recruitment, people with impairments faced a number of distinct challenges in the course of the UKF\&TV labour process. First, mainstream UKF\&TV production was characterized by high speed and intensive working environments, long hours, tight deadlines and frequent and substantial travel. This required a workforce which was flexible and responsive to the demands of a fast changing industry and able to cope with extreme working conditions. Judi (wheelchair user) and Ross (blind) both referred to these as 'macho ideals':

It's that kind of thing of ' $\mathrm{Oh}$... the other day it was a 10 hour film shoot' and somebody says, 'Mine was 15 hours and I was up to my neck in water' ... [it's] competitive ... and if you can't sort of work to those macho ideals then you don't belong. (Judi)

Long days could form constraints for women, who find it difficult to reconcile this with care responsibilities. In addition to the length of the working day, being unable to engage with a high-speed labour process further challenged the approximation to ideal worker status for those with impairments:

You have these deadlines, it's very fast moving, you need to get the jobs done [and] move on very quickly ... They don't really want to include a deaf person there. It's kind of like a thorn in the side ... it slows down their cogs ... Location is very spur of the moment, very last minute, something's happening, it's like 'run and film it', and I think their attitude is 'Oh ... deaf ... it kind of slows down the production'; they can't really afford that'. (John)

Second, geographical flexibility has similarly been shown to constrain women's participation, but the rapidly changing spatialities of the work (e.g. location work) produced a number of further barriers to workers who had impairments that impacted on mobility:

You cannot work without some adaptations to the workplace. You cannot get in the building ... or you cannot get into places you need to work or whatever, you know, you can't read your material ... so immediately we had barriers in terms of, you know, the physical environment'. (Rowan)

The impact of the physical work environment on the ability of workers with impairments to participate has been noted in other studies, particularly those focusing on adjustments; however, within UKF\&TV this has a particularly acute impact. The requirement to be highly mobile in order to move between sites on a project and the short-term nature of contracts meant that adjustments could not be made on a permanent basis and this constrained some workers. 
Third, difficulties in communication were also widely cited by participants as disabling in their ability to get on at work, as well as for networking, a challenge not noted in the literature as affecting other minorities. Timothy (deaf) said that there was more awareness and support in minority programming, but that since he had moved into a mainstream programme he had found it harder to manage:

In the office there's lots of talking ... banter and conversation going on, and it's difficult for me to be part of that, so sometimes I feel that I have to ... put my hand up and say 'What's going on? I need to be included' ... I've noticed ... there'll be discussions about that story that [I'm working on, that] I'm not involved in ... I'm not sure if they're deliberately doing it or they just haven't thought about me ... Maybe they think it's easier just to discuss it without the deaf person involved.

Frequently reconstituted working teams meant that Timothy and others had to renegotiate access and inclusion with colleagues, as well as adjustments to the physical environment, with each new project or contract. This created barriers in both the labour process and also to networking within the job, reflecting the interconnectedness of processes of identifying and securing work in the industry. In this sense, both the social dynamics of the workplace - socializing and communicating - as well as the way work is organized and including rapidly changing work sites, presented challenges to workers with impairments that do not appear to constrain other minority workers.

\section{Conclusion}

In addressing its first research question, this article has argued that the participation of people with impairments in UKF\&TV is low because they are 'doubly disabled'. They are firstly disadvantaged in the labour markets characteristic of the creative and cultural industries in similar ways to those excluded on a basis of gender, race and class. They are secondly disadvantaged by the labour processes and work organization which are constitutive of the sector. While previous research has focused largely on the labour market, by including the labour process the distinctive ways in which workers with impairments are disadvantaged becomes evident.

Since both the labour market and the labour process are fundamentally shaped by the model of production in UKF\&TV, following Eikhof and Warhurst (2013), this has to be understood as key in creating and maintaining inequalities for people with impairments and other minorities more generally. However, addressing the second research question, while workers with impairments share many of the sources of exclusion with other minority groups (e.g. in recruitment practices and in terms of spatial flexibility), they also face very specific barriers relating to the social dynamics and physical elements of the labour process itself. Disabled workers faced multiple barriers to entry and subsequently experienced both glass ceilings and glass partitions, often finding themselves ghettoized in specialist programming or expelled from the UKF\&TV labour market all together.

While we have strong and consistent accounts of inequality based on gender and ethnicity (and to a lesser extent, class) in UKF\&TV employment, the analysis presented 
here does not propose an 'add disability and stir' approach. Instead, it is suggested that disabled people face qualitatively different barriers to employment than other minorities. The frequency of entry into the labour market means that workers with impairments need to regularly overcome assumptions about their capabilities and engage in networking. This generates multiple opportunities to exclude - via catnets (Rydgren, 2004) and other network effects which have been described as the 'dark side of social capital' (Antcliff et al., 2007), and through stereotyping.

The form of the labour process itself, premised on the macho, resilient, highly mobile ideal worker, hinders equal participation for workers with impairments. While there are many accounts addressing the way in which the serial recruitment of workers into UKF\&TV proves exclusionary for non-white, non-male, non-middle-class workers, few accounts have investigated the labour process itself. However, disaggregating the model of production into these two sites is conceptually useful as a lens for examining the difference that impairment makes to workers' experiences of exclusion. Ableist values shape the design of the capitalist production process itself (Foster and Wass, 2012), and the UKF\&TV production model is no exception. It demands a body able to withstand high levels of work intensity, variability of working environment and long working days. There are clear difficulties in negotiating adjustments in the UKF\&TV workplace environment which involve both spatial mobility and short-term project working. The fragmentation of the industry means that such exclusions are not only endemic, but systemic - both in recruitment and in the ways in which it shapes the labour market - and also, importantly, within the labour process itself.

Disability 'is a social construction in the most obvious sense' (Hirschman, 2012: 398). In the case of UKF\&TV, the labour market and the labour process present dual and connected sites of socially constructed disablement. Practices such as short-term, freelance work and its expansion throughout UKF\&TV are disabling for workers with some types of impairment. Given that work and labour markets with these characteristics are seen as increasingly paradigmatic and normative, then resilience, endurance and an ability to withstand intensive working practices are likely to constitute the necessary characteristics of the ideal worker across other sectors where non-traditional, short-term, projectbased or freelance work requires frequent entry into the labour market. This calls into question optimistic pronouncements on the creative economy and its associated working conditions as a vehicle for social and economic development. On the contrary, it suggests there is potential for the exclusion of people with impairments to grow alongside the normalization of short-term, contract-based work.

\section{Acknowledgements}

The authors wish to acknowledge the original data collection and analysis carried out during this study by Dr Wing Fai Leung and Ms Juno Kurian and the additional data analysis carried out by Ms Zlatina Rankova. They also wish to acknowledge the invaluable contribution of three anonymous referees.

\section{Note}

This article was submitted by the authors while Kate Hardy was an Editor of Work, employment and society. The article followed the process as detailed in the BSA Terms of Reference. The 
article was edited by the Chair of the Board and at the revision stage by a member of a new Editorial Team. The article underwent the journal's usual peer review process with a minimum of three peer reviewers, and for this article, including at least one external non-Board reviewer. During the process the authors had no access to information regarding their article beyond that available to all authors.

\section{Funding}

This research was funded by the European Social Fund as part of the Diversity in Practice project, an EQUAL initiative.

\section{References}

Acker J (1990) Hierarchies, jobs, bodies: a theory of gendered organization. Gender \& Society 4(2): 139-58.

Antcliff V, Saundry R and Stuart M (2007) Networks and social capital in the UK television industry: the weakness of weak ties. Human Relations 60(2): 371-93.

Ashton D (2014) Making media workers: contesting film and television industry career pathways. Television \& New Media 16(3): 275-94.

Barnes C and Mercer G (2003) Disability. Cambridge: Polity Press.

Berthoud R (2008) Disability employment penalties in Britain. Work, Employment and Society 22(1): 129-48.

Bhavnani R (2007) Barriers to Diversity in Film: A Research Review. London: UKFC.

Blair H (2001) 'You're only as good as your last job': the labour process and labour market in the British film industry. Work, Employment and Society 15(1): 149-69.

Born G (2004) Uncertain Vision: Birt, Dyke and the Reinvention of the BBC. London: Secker and Warburg.

British Film Institute (BFI) (2013) Statistical Yearbook. London: BFI.

Burke PJ and McManus J (2015) Art For a Few: Exclusion and Misrecognition in Art and Design Higher Education Admissions. London: HEFCE.

Carbado DW (2013) Colorblind intersectionality. Signs 38(4): 811-45.

Cooper M (2000) Being the 'go-to-guy': fatherhood, masculinity, and the organization of work in Silicon Valley. Qualitative Sociology 23(4): 379-405.

Cranford CJ, Vosko LF and Zukewich N (2003) Precarious employment in the Canadian labour market: a statistical portrait. Just Labour 3: 6-22.

Dex S, Willis J, Paterson R and Shepherd E (2000) Freelance workers and contract uncertainty: the effects of contractual changes in the television industry. Work, Employment and Society 14(2): 283-305.

Eikhof DR and Warhurst C (2013) The promised land? Why social inequalities are systemic in the creative industries. Employee Relations 35(5): 495-508.

Fevre R, Robinson A, Lewis D and Jones T (2013) The ill-treatment of employees with disabilities in British workplaces. Work, Employment and Society 27(3): 288-307.

Florida R (2005) The Flight of the Creative Class. New York: HarperCollins.

Foster D and Wass V (2012) Disability in the labour market: an exploration of concepts of the 'ideal worker' and organisational 'fit' that disadvantage employees with impairments. Sociology 7(4): 705-21.

Gill R (2002) Cool, creative and egalitarian? Exploring gender in project-based new media work. Information, Communication \& Society 5(1): 70-89.

Grugulis I and Stoyanova D (2012) Social capital and networks in film and TV: jobs for the boys? Organization Studies 33(10): 1311-31. 
Hirschman N (2012) Disability as a new frontier for feminist intersectionality research. Politics and Gender 8(3): 396-405.

Holgate J and Mckay S (2007) Institutional barriers to recruitment and employment in the audio visual industries: the effect on black and minority ethnic workers. London: Working Lives Research Institute.

Hughes B (2002) Bauman's strangers: impairment and the invalidation of disabled people in modern and post-modern cultures. Disability \& Society 17(5): 571-84.

Jones M and Wass V (2013) Understanding changing disability-related employment gaps in Britain 1998-2011. Work, Employment and Society 27(6): 982-1003.

Kelly EL, Ammons SK, Chermack K and Moen P (2010) Gendered challenge, gendered response: confronting the ideal worker norm in a white-collar organization. Gender \& Society 24(3): 281-303.

Lee DJ (2011) Networks, cultural capital and creative labour in the British independent television industry. Media, Culture \& Society 33(4): 549-65.

Low Pay Commission (2011) National Minimum Wage: Low Pay Commission Report 2011. London: Department for Business, Innovation \& Skills.

National Union of Journalists (NUJ) (2007) Work Experience Guidelines. London: NUJ.

Oliver M (1983) Social Work with Disabled People. Basingstoke: Macmillan.

Oliver M (1996) Understanding Disability: From Theory to Practice. Basingstoke: Macmillan.

PACT (2007) Work Experience Guide. London: PACT.

Percival N and Hesmondhalgh D (2014) Unpaid work in the UK television and film industries: resistance and changing attitudes. European Journal of Communication 29(2): 188-203.

Randle K, Kurian J and Leung WF (2007) Creating Difference. Hatfield: University of Hertfordshire.

Rees-Davies A and Frink B (2014) The origins of the ideal worker: the separation of work and home in the United States from the market revolution to 1950. Work and Occupations 41(1): 40-62.

Robson C (1993) Real World Research: A Resource for Social Scientists and Practitioner Researchers. Oxford: Blackwell.

Roulstone A (2002) Disabling pasts, enabling futures? How does the changing nature of capitalism impact on the disabled worker and jobseeker? Disability \& Society 17(6): 627-42.

Roulstone A and Williams J (2014) Being disabled, being a manager: 'glass partitions' and conditional identities in the contemporary workplace. Disability \& Society 29(1): 16-29.

Rydgren J (2004) Mechanisms of Exclusion: ethnic discrimination in the Swedish labour market. Journal of Ethnic and Migration Studies 30(4): 697-716.

Saundry R (2001) Employee relations in British television - regulation, fragmentation and flexibility. Industrial Relations Journal 32(1): 22-36.

Saundry R, Antcliff V and Stuart M (2006) 'It's more than who you know' - networks and trade unions in the audio-visual industries. Human Resource Management Journal 16(4): 376-92.

Scharff (2015) Equality and Diversity in the Classical Music Profession. London: Kings College London.

Shakespeare T (2014) Disability Rights and Wrongs, 2nd Edition. London: Routledge.

Shakespeare T and Watson N (2002) The social model of disability: an outdated ideology? Research in Social Science and Disability 2: 9-28.

Shuey M and Jovic E (2013) Disability accommodation in nonstandard and precarious employment arrangements. Work and Occupations 40(2): 174-205.

Siebert S and Wilson F (2013) All work and no pay: consequences of unpaid work in the creative industries. Work, Employment and Society 27(4): 711-21.

Skillset (2005) Survey of the audio visual industries' workforce 2005. London: Skillset. 
Skillset/UKFC (2008) Feature film production workforce survey report 2008. London: Skillset/ UKFC.

Terzi L (2004) The social model of disability: a philosophical critique. Journal of Applied Philosophy 21(2): 141-57.

Thanki A and Jefferys S (2007) Who are the fairest? Ethnic segmentation in London's media production. Work Organisation, Labour and Globalisation 1(1): 108-18.

Thomas C (2007) Sociologies of Disability and Illness: Contested Ideas in Disability Studies and Medical Sociology. London: Palgrave Macmillan.

UK Film Council (UKFC) (2003) Success through Diversity and Inclusion. London: UKFC.

UK Government (no date) Disability Prevalence Rates. Available at: https:/www.gov.uk/government/uploads/system/uploads/attachment_data/file/321594/disability-prevalence.pdf (accessed 27 May 2016).

Vasey S (1997) Sorry I can't make the tea. In: Pointon A and Davies C (eds) Framed: Interrogating Disability in the Media. London: British Film Industry, 135-40.

Yuval-Davis N (2006) Intersectionality and feminist politics. European Journal of Women's Studies 13(3): 193-209.

Keith Randle is Professor of Work and Organisation at the Hertfordshire Business School, UK. He has a particular interest in exclusion and inequalities in the creative and cultural industries internationally and has published widely on work and employment in the film and television industries. In 2013, he co-established the interdisciplinary Creative Economy Research Centre (CERC) at the University of Hertfordshire with the aim of bringing together research interests in Business, Humanities and the Creative Arts.

Kate Hardy is a Lecturer in Work and Employment Relations at the University of Leeds. Her research interests include paid and unpaid work; gender; agency; the sex industry; materialist feminism; collective organizing; political economy; the body; disability and theorizing work and employment. Her work has been widely published academically and disseminated through radio and news media. She has co-authored a monograph with Teela Sanders, entitled Flexible Workers: Labour, Regulation and the Political Economy of the Stripping Industry. Kate is committed to developing methodologies which work alongside research participants, in order to undertake socially and politically transformative research.

Date submitted July 2014

Date accepted March 2016 
Appendix I. Interview Respondents: Summary of Impairments and Professional Roles.

\begin{tabular}{|c|c|c|}
\hline Name & Impairment & Role(s) \\
\hline Ali & Deaf & TV presenter \\
\hline Alice & Wheelchair user & Extend co-ordinator \\
\hline Ben & Phocomelia (arms) & Actor, screenwriter \\
\hline Catherine & Profoundly deaf & Independent TV programme developer \\
\hline Chris & Blind & Actor \\
\hline Felicity & Wheelchair user & Radio producer \\
\hline Glen & Visual impairment & Journalist, age and disability correspondent \\
\hline Holly & Unspecified disability & $\begin{array}{l}\text { Freelance disability quality trainer and } \\
\text { consultant }\end{array}$ \\
\hline James & Hearing impairment & $\begin{array}{l}\text { Researcher for specialist disability } \\
\text { programme and writer }\end{array}$ \\
\hline John & Deaf & $\begin{array}{l}\text { Signing presenter, cameraman, managing } \\
\text { director of small and/or medium-sized } \\
\text { enterprise }\end{array}$ \\
\hline Judi & Wheelchair user & Film maker, writer, director, producer \\
\hline Karen & Unspecified disability & CEO, multimedia company \\
\hline Lori & Phocomelia & $\begin{array}{l}\text { Researcher, arts development officer, } \\
\text { freelance mentor, theatre designer }\end{array}$ \\
\hline Morgan & Through accident, wheelchair user & Producer, theatre director, artistic director \\
\hline $\begin{array}{l}\text { Nasir + } \\
\text { helper }\end{array}$ & Cerebral palsy (wheelchair user) & Freelance film maker \\
\hline Paul & Dwarfism & $\begin{array}{l}\text { Small business owner, consultant, comedian, } \\
\text { presenter }\end{array}$ \\
\hline Rosie & Unspecified disability & Freelance filmmaker \\
\hline Ross & Blind & Journalist, political correspondent, reporter \\
\hline Rowan & Impaired vision & Film maker, writer, director \\
\hline Stephen & $\begin{array}{l}\text { Wheelchair user, limited arm and } \\
\text { hand movement through accident }\end{array}$ & Assistant producer \\
\hline Timothy & Deaf & Assistant producer \\
\hline
\end{tabular}

